\title{
La constitución de la organización comunista de los intelectuales, Madrid, 1953-1954
}

\author{
FELIPE Nieto \\ Doctor y Profesor tutor. Dpto. H. ${ }^{\mathrm{a}}$ Contemporánea. UNED \\ Centro de Investigaciones Históricas de la Democracia Española \\ La constitución de la organización comunista \\ de los intelectuales, Madrid, 1953-1954
}

\begin{abstract}
RESUMEN
ABSTRACT

La lucha antifranquista promovida por el partido comunista de España, PCE, entre los intelectuales y universitarios españoles, comenzó en 1954 y fraguó en 1956 gracias al trabajo de Jorge Semprún, futuro Federico Sánchez, enviado clandestino de la dirección comunista radicada en París. Los informes enviados a la dirección son un buen análisis de la situación de la cultura española en los 50 y muestran el lento progresar de la implantación de los comunistas que rendirá efectos destacados dos años después.

PALABRAS CLAVE antifranquismo, intelectuales, comunistas.

The antifranquist struggle, instigated from the Spanish Communist Party, PCE, among the intellectuals and university students, begun in 1954 and settled in 1956 thanks to Jorge Semprún's work, who worked as the undercover envoy of the communist leadership exiled in Paris. The reports addressed to the communist leadership serve as a good analysis of the cultural situation in Spain in the 50's, and show the steady improvement of the communist roots, which showed his effect in 1956.

KEY WORDS

Antifrancoism, intelectuals, comunists
\end{abstract}


Después de un periplo de un mes por varias ciudades españolas en la primavera de 1953, primer viaje de regreso clandestino a su país desde el exilio en 1936, Jorge Semprún emite un informe a la dirección de su partido en el que da cuenta de los contactos y entrevistas mantenidos y de las perspectivas políticas abiertas ${ }^{1}$. Sus conclusiones generales deben servir de punto de partida para la entrada en acción inmediata. Aparece aquí una elaboración personal de lo visto y vivido a lo largo de un mes tan intenso. Resultó inevitable poner en relación sus impresiones y sensaciones inmediatas con el recuerdo lejano del país abandonado en la adolescencia: «Desde luego, es imposible darlas todas: después de 16 años de ausencia, el regreso, aunque sólo sea por un mes, produce demasiadas impresiones. Se necesitaría una novela. Intentaré destacar lo importante». En las rápidas pinceladas del informe con que describe el país que ha visitado parece haber captado con bastante precisión la realidad española. La narración revela más los modos del futuro escritor que los del informador burocrático de rigor.

"Solo se ven dos cosas: fascismo y miseria (con el correspondiente lujo desenfrenado en reducidísimos sectores). En Barcelona y en Madrid: la Vía Layetana y la calle de Alcalá, por las mañanas: bancos, bancos y más bancos, y delante de cada puerta de aquellos, la pareja de policía armada. Luego, en plena BarceIona, calle Sanjurjo, las chabolas, y en Madrid, en cuanto se aparta uno del casco céntrico de la ciudad, la brutalidad de la miseria. Como estribillo alucinador, el grito de los ciegos que en cada esquina venden los cupones de la lotería especial: «¡Para hoy, para hoy! ¡Quedan cinco iguales! ¡Para hoy!» Al lado, algún escaparate de tienda de lujo y algún «Cadillac» rutilante».

Semprún se admira de que el régimen se sostenga «si no hay fascistas», si nadie parece comentar ni interesarse por lo que atañe al régimen. Sólo podría explicarse por el agobio de la miseria generalizada que lleva a la mayoría de la población a preocuparse exclusivamente por la subsistencia — «la palabra peseta es la que con mayor frecuencia se oye pronunciar»- y a olvidarse del sistema y su propaganda, lo que sin duda es fomentado por «el cinismo del régimen» que promociona «el fútbol profesional y los toros, como forma de embrutecimiento... el «kubalismo» como enfermedad de gran parte de la juventud».

La decadencia y el atraso han sorprendido al viajero desde que cruzó la frontera española, "parece que ha sido transportado uno a un país de hace medio siglo». La pobreza, en el paisaje y en las gentes, salta a la vista. En las ciudades los contrastes son ostentosos. El viajero se detiene especialmente en la descripción de su ciudad. No puede evitar la comparación con los «recuerdos de niño del año 36. Madrid, ciudad mimada del régimen», presenta un centro suntuoso, «el casco céntrico está muy bonito», con bancos, coches «haiga» y cafeterías de estilo americano... «Luego se constata que con apartarse un poquito del centro cambia

1 Sobre algunos aspectos de la situación entre los intelectuales españoles. (Informe sobre un viaje de un mes por el Interior), 68 f. (faltan 4, del 42 a 45), s. f. (1953), AHPCE, Intelectuales y Movimiento estudiantil, Jacq., 20-24. 
radicalmente el panorama». Junto a esto, la fuerza represiva, la presencia ubicua «de la fuerza armada, del aparato de represión del régimen: guardia civil, policía armada, soldados, guardavías armados, y más guardia civil y más policía armada».

Estas impresiones externas no deben sorprender a ningún comunista. Cumple destacar al autor del informe «la absoluta exactitud científica, minuto por minuto comprobada, del análisis de la situación española que en los materiales de la Dirección de nuestro Partido se hace». El viajero ha comprobado que gracias a esos materiales ha podido aclarar muchas situaciones a los españoles perplejos $y$, sobre todo, ha podido ponerlos en disposición activa y movilizarlos, en la confianza de que en el actuar se dan «posibilidades de éxito insospechadas».

La estancia en Madrid coincide con la Feria del Libro, expuesta en el paseo Recoletos, cuya visita le sirve para extraer una visión del panorama editorial del momento. Se compran pocos libros porque, como todo el mundo comenta, son muy caros. Abundan los libros de doctrina religiosa, novela rosa, libros de estilo americano. Pero el viajero pareció observar cierto interés por la poesía y la novela española actual, como Los cipreses creen en Dios de Gironella, Nosotros los Rivero de Dolores Medio, etc. Destaca, por otro lado, la literatura antisoviética y anticomunista: «Algo profundamente significativo: muy a la vista, un libro de Trotsky, al lado Burnham y Foster Dulles. Dios los cría y ellos de juntan", comenta resuelto y ortodoxo en esta ocasión el inconfeso lector a hurtadillas del asesinado dirigente de la revolución rusa.

Este conjunto impresionista de escenas diversas que recrea el viajero es producto en buena parte de su visión emocionada por el reencuentro con el país de origen. Traduce simpatía, compresión, proximidad y hasta compasión por el malestar y sufrimiento del pueblo español, víctima de su régimen dictatorial. Destacan también las fuertes agarraderas ideológicas características del militante comunista del momento, plenamente acordes con la doctrina del partido que representa sin el más leve deseo de desentonar. Ellas, sin embargo, no le privan de elaborar una visión personal sustanciosa de la España recorrida. Su impresión final, fruto de ambas visiones, la analítica y la militante, no deja de ser optimista pese a la miseria, la iglesia y sus ceremoniales y una vigilancia policial permanente e ineficaz al mismo tiempo:

"Como impresión predominante, pues, queda la de la extraordinaria vitalidad del pueblo español. ... enorme reserva de fuerza política, en gran parte todavía inutilizada. No da España impresión estática, ni siquiera a ojos vistas. ... se nota que grupos y capas sociales enteras se hallan en movimiento. Una frase vuelve como estribillo en todas las conversaciones que se han tenido: «el día en que se organice...» Y está organizándose».

Se cierra este informe abierto al optimismo, después de haber descubierto un territorio de posibilidades de actuación política inmensas. Lo que se correspondía con las previsiones comunistas: «La situación de los intelectuales españoles... con- 
firma en todo punto la justeza del análisis de la Dirección del Partido, la justeza de la línea política en este aspecto del trabajo. De cara al futuro, las posibilidades rebasan con mucho, a mi parecer, las previsiones más optimistas que podían hacerse».

Como trabajo inmediato, Semprún propone hacer de revistas como Cuadernos de Cultura el órgano de intervención de los intelectuales españoles, difundir revistas del partido, como Nuestro Tiempo, aunque «elevando para ello la calidad de su contenido", difundir las revistas literarias del partido comunista francés, intervenir en la radio «desenmascarando las posiciones demagógicas de Falange, la Iglesia...", promover revistas y ediciones legales y, finalmente, "dedicar una especial atención a la formación política e ideológica de un grupo de intelectuales que se transformarán, según la indicación de la camarada Dolores, en «propagandistas del marxismo", en organizadores del movimiento democrático antifranquista».

A la vista de este extenso informe conviene empezar por subrayar el entusiasmo, personal y político, de Semprún. Sin embargo, hay algo certero en el breve recorrido sempruniano por España. El año 1953, 14 años después de finalizada la Guerra Civil, presenta, por decirlo con el tópico al uso, una luz al final del túnel. Lo que se hace visible en la recuperación económica, -recuperación de los niveles de renta de $1936^{2}$-, en una cierta moderación de la política represiva, con la reducción de las condenas a muerte sobre todo y en un gobierno, el de 1951, que muestra algunos signos integradores, al menos en el sector de la cultura. Resultado de todo ello será el indudable renacer cultural de los años 50, protagonizado por gentes progresivamente distanciadas del régimen y una nueva actividad opositora, en el movimiento obrero y en los intelectuales. Como ha escrito Ruiz Carnicer: «Esta década de los cincuenta difícilmente puede ser calificada de «tiempo de transición» o de tiempo perdido. Por el contrario, es quizá el momento clave del régimen, en la medida en que es un período de estabilidad interna y, a la par, de agotamiento de las expectativas políticas, culturales o sociales que alguna vez el régimen del 18 de julio hubiera podido concitar. Por ello es un momento también de maduración de capas importantes de la sociedad española que pasan de la sumisión por el terror de la inmediata posguerra a posiciones de mayor independencia, que experimentan un evidente alejamiento del régimen, primero intuitivo y luego más razonado...» ${ }^{3}$. A este proceso asiste Semprún desde su primer viaje y advierte las posibilidades de actuación bajo dirección comunista, muchas de las cuales se podrán ir desplegando a lo largo de la década.

Algunas de estas mismas realidades emergentes habían sido bien percibidas por los visitantes procedentes del exterior, como eran los residentes en París enviados por el PCE, así como por otros viajeros, de distinto signo y carácter político.

2 FUSI. J P:, Franco. Autoritarismo y poder personal, Madrid, 1985 (3. a), p. 132. GARCÍA DELGADO, J.L. y JIMÉNEZ, J. C., Un siglo de España. La economía, Madrid, 1999.

3 GRACIA GARCÍA, J. y RUIZ CARNICER, M. A.: La España de Franco (1939-1975). Cultura y vida cotidiana, Madrid, 2001, p. 212. 
El poeta Jorge Guillén, por ejemplo, en 1951, se expresaba en términos similares a los de Semprún al hablar de Madrid y del régimen franquista: «No he tropezado aún con un «creyente» en el régimen actual... Madrid, al parecer, sigue siendo la ciudad alegre y confiada. «Sí», me respondió alguien. «Pero nadie está conforme con el Gobierno»... España vive en un presente sin futuro, sin posible solución normal. (¡Gran obra de Franco!)... La sociedad española va transformándose, a pesar de todo... Madrid está muy cuidado, agradable, más lujoso que antes, más moderno. El ritmo de los tiempos se impone... Franco no preside -me pareceuna España antigua. Entre las dos fuerzas predominantes - Clero y milicia- las cosas van cambiando, deshaciéndose...» ${ }^{4}$. En consecuencia de todo lo visto y anotado, con este primer viaje de Semprún quedó preparado el terreno para la futura actividad política comunista entre los intelectuales.

\section{PRESENCIA Y ACTIVIDAD DE JORGE SEMPRÚN (EDERICO) EN MADRID}

El responsable de ese trabajo en Madrid desde ese mismo año es Jorge Semprún, por decisión de los dirigentes del buró político del PCE residentes en París. Poco a poco se irá rodeando de un equipo de activistas, inmersos en los diversos campos de la actividad intelectual. El primero y más importante es Ricardo Muñoz Suay, antiguo dirigente de la JSU, conocido de Santiago Carrillo, recuperado para el partido comunista a partir de su vista a París en el verano de 1953 y de las entrevistas que mantuvo con Semprún ${ }^{5}$. Su colaboración en la prensa y sus amplios contactos en medios culturales y periodísticos serán a partir de ahora una fuente información muy valiosa para el PCE. Pronto se sumarán otros nombres significados.

En la dirección exterior del PCE se toma conciencia de que la situación española está empezando a evolucionar de un modo que ellos no preveían, antes de las informaciones de Semprún y otros «viajeros» en misión informativa por España. Ante un grupo de dirigentes reunidos en París, Carrillo presenta una nueva realidad, originada en los pactos del régimen franquista con los norteamericanos. Tan nefastos son sus efectos, a juicio de Carrillo, que a partir de ahora se podrá esta-

4 Carta desde Roma (27 de octubre de 1951) a Pedro Salinas, cit. en apéndice de Ib., p. 405. La carta se incluye en el volumen Pedro SALINAS/Jorge GUILLÉN, Correspondencia (1923-1951), edición de Andrés Soria Olmedo, Barcelona, 1992, pp. 582-583.

5 Se encontraba en la capital francesa participando en el rodaje de Sangre y luces, una historia de género taurino, dirigida por Georges Rouquier. Muñoz Suay sería el codirector, o director de la versión para España, aligerada y adecuada a los criterios de la rigurosa censura española, Entrevista a Eduardo Ducay, Madrid, 14 de octubre de 2004; RIAMBAU, E., Ricardo Muñoz Suay. Una vida en sombras. Biografía, Barcelona, 2007, pp. 193-196, 217-221; SALVADOR MARAÑÓN, A., De ¡Bienvenido Mr. Marshall! a Viridiana. Historia de UNINCI: una productora cinematográfica española bajo el franquismo, s. I. (Madrid), 2006, pp. 225-230. Sobre su militancia comunista v. MUÑOZ SUAY, R.: «Fragmentos de una clandestinidad permanente», Tiempo de Historia, n. ${ }^{\circ}$ 92-93, pp. 66-69. V. también, MOLINA FOIX, V., «Ricardo Muñoz Suay, cineasta. La lucidez es el arma de la libertad», El País, 3 de septiembre de 1995 V. igualmente, MORÁN, G.: Miseria y grandeza del Partido Comunista de España 1939-1985, Barcelona, 
blecer una división nueva entre los españoles: «Sin que ello constituya una línea divisoria rígida, la división no será entre las antiguas derechas e izquierdas, ni entre los que estuvieron del lado de allá y del lado de acá en nuestra guerra, sino que frente al pacto yanqui-franquista se producirán desplazamientos políticos y la divisoria se producirá en torno al dilema: Por España o con los yankis; por la independencia nacional o... Se creará una correlación de fuerzas distinta, que ya comienza a perfilarse». Una nueva división del país parece ver establecida el PCE, más acorde con los tiempos, que viene a sustituir, a superar, la división vigente, según el régimen, de derechas e izquierdas irreconciliables. Resulta sugerente porque anticipa la necesidad de superación de criterios del pasado, si bien no llega a concretar una propuesta para el inmediato porvenir ${ }^{6}$.

Centrándose en los medios intelectuales, los participantes en la discusión parten, al igual que Semprún o Muñoz Suay, del creciente descontento que afecta a gentes identificadas hasta ahora con el régimen y, sobre todo, a nuevas generaciones de universitarios e intelectuales. Se muestran convencidos de que son pocos los intelectuales que den su apoyo al régimen: «Hoy no se puede hablar de una intelectualidad franquista,» resume Carrillo. «Todo lo que hay hoy de algún valor, o está con nosotros, o por lo menos está contra el franquismo", a partir de unas fuerzas heterogéneas, liberales, católicos, insatisfechos en general con «la ideología oficial»».

Las diversas intervenciones abundan en lo mal que está la situación española, «podrida y en descomposición...» Ahora bien, eso obliga a proceder con cautela, sin precipitación, agrupando las distintas fuerzas. Juntas todas pueden lograr el objetivo, pues son muchos los elementos dispuestos a luchar con el partido comunista, cuya organización crece prácticamente en todas las provincias españolas, afirma Carrillo optimista. La lucha compete a todas las fuerzas, no sólo a la clase obrera. En este contexto adquiere relevancia la contribución de los intelectuales a la lucha general antifranquista ${ }^{7}$. La importancia de la disconformidad de las fuerzas intelectuales se acrecienta en la perspectiva histórica de algunos dirigentes, «jóvenes" según el criterio jerárquico del partido comunista, pero veteranos en realidad, como Carrillo, que escribe: «Examinando la importancia de este movimiento, si recordamos el papel que jugaron, por ejemplo, los estudiantes al final de la monarquía, pensamos el papel que pueden jugar hoy en la lucha por la independencia nacional, por la democracia».

1986, p. 232.

6 Discusión sobre el informe St. (Santiago Carrillo), (22. octubre. 1953), AHPCE, documentos PCE, Carpeta 34, 43 pp. El texto del documento está cifrado en lo que respecta a nombres propios, de militantes, de regiones, etc. pero no se dispone de claves. V. MORAN, G., Miseria..., p. 234, que sitúa entre los presentes en la reunión de París a Carrillo, Uribe, Mije, Gallego y Errandonea. No habla de Román Serradell.

7 Como recuerda Miguel Núñez, que trabajaba este año cerca de la Comisión del Interior en París y en relación con la actividad de los intelectuales, "se empieza a no menospreciar a los intelectuales», gracias al trabajo de Semprún y al suyo. Entrevista con Miguel Núñez, Madrid, 10 de julio de 2003. V. igualmente, NúÑEZ, M.: La revolución y el deseo. Memorias, Barcelona, 2002, pp. 250-253. 
A partir de ahora el partido comunista ya no utilizará cuadros enviados al interior como años atrás, sino instructores capaces de formar militantes y organizar su actividad a las órdenes de la dirección exterior. Los activistas comunistas tienen que organizar a los creadores, a los escritores, a los poetas, a los artistas, que no deben creerse parte de una elite social aparte, y que necesitan toda la orientación y perspectivas para una lucha que se desarrolla en relación con otros sectores del pueblo por ellos ignorados, pues «bien utilizados, estos núcleos de intelectuales pueden jugar un papel muy positivo para movilizar al pueblo"... Los intelectuales buscan al partido, lo necesitan para comprender los nuevos problemas que surgen, a algunos incluso, proclama Carrillo, «les atrae nuestro humanismo».

Los instrumentos de acción del partido serán el incremento de la propaganda por medio de prensa, libros, etc. «Antes lo que se pedía eran cuadros y dinero. Hoy se pide propaganda", afirma Carrillo. La creación de una revista vuelve a aparecer como el pilar central del trabajo con los intelectuales. Debe difundir legalmente las ideas del partido - las concepciones artísticas (entiéndase el realismo social), la paz: «Puede ser una revista de la juventud universitaria, y que nos sirva para penetrar entre ella».

El instrumento más importante de los aprobados en esta discusión es un manifiesto del partido dirigido expresamente a la intelectualidad española. La idea fue sugerida por Vicente Uribe y recogida por Carrillo: «Es una idea muy original, porque nunca nos habíamos dirigido a los intelectuales con un documento del Partido...» Carrillo anuncia que este documento se está elaborando ya y que pronto podrá ser discutido. Este proyecto de lo que acabará llamándose Mensaje a los intelectuales patriotas debía llevar ya tiempo gestándose. En su entrevista en San Sebastián Semprún obtuvo el apoyo de Celaya a la idea de escribir y propagar un mensaje de ese tipo.

\section{LOS PRIMEROS AGITADORES COMUNISTAS ENTRE LOS INTELECTUALES}

A partir de todas estas informaciones recopiladas, con los objetivos y planes inmediatos trazados, se puede dar por constituida la organización de los intelectuales en Madrid. De esta organización vendrá el mayor éxito político y el prestigio suficiente para convertirse en la fuerza más importante de oposición intelectual de los años 50. Gracias a los resultados de su trabajo, los estrategas de esa lucha serán catapultados a los primeros puestos de dirección del partido. Lograrán desplazar, en el breve lapso de poco más de dos años, a los antiguos dirigentes, procedentes de la época de la Guerra Civil, los que contra viento y marea de las más cambiantes coyunturas nacionales e internacionales venían dirigiendo el partido de forma ininterrumpida e incuestionada hasta entonces, en el ya largo período del exilio.

Desde París pilotan la nave Santiago Carrillo y su estrecho colaborador Víctor Velasco. Junto a ellos, Semprún cita, trabajando en la «Comisión del Interior» a lo 
largo de sus años de instructor en Madrid —los primeros, es de suponer-, los siguientes nombres: Grimau, Romero Marín, Eduardo García, Antonio Gros, Miguel Núñez, Abelardo Gimeno, Serrán, Freile, etc. ${ }^{8}$

Esta estructura se apoya en un precario y diversificado equipo de intelectuales, militantes comunistas, radicado en el interior, que es el que empieza a dirigir Semprún (Federico), con Muñoz Suay como su representante permanente, responsable del sector de los intelectuales y encargado específicamente de las gentes del cinema, como se escribía en aquellos años. En este campo contaba con el apoyo firme y la voluntad inquebrantable del más veterano militante, Juan Antonio Bardem.

Junto a ellos se situaba el pintor y grabador José García Ortega, Pepe Ortega, alias Enrique, militante lleno de fe y entusiasmo por la causa comunista e infatigable activista en los medios de los artistas plásticos ${ }^{9}$. El Dr. José Hernández iba a ser otro valor seguro, en este caso para el trabajo del partido en los medios profesionales. También su casa y su centro de trabajo, su clínica, se convierten en oasis acogedor y seguro para los militantes comunistas en misión por Madrid. El poeta Gabriel Celaya es el referente para el trabajo entre los escritores, el militante más firme con que cuenta la organización comunista para introducirse en el mundo de las editoriales y revistas de creación literaria que están adquiriendo amplio desarrollo. Tiene previsto fijar su residencia en Madrid próximamente. Con todos estos elementos se puede considerar que se ha formado el embrión del comité de intelectuales comunistas de Madrid. A ellos se sumará Enrique Múgica, cuando se traslade a Madrid a comienzos del curso siguiente y ponga en marcha la organización comunista universitaria.

A partir de aquí empieza la expansión. En torno a estas cabezas de puente en los diferentes sectores culturales, el PCE trata de extender su influencia mediante la red de contactos que viene tejiendo paso a paso, en la que se incluyen los colaboradores ocasionales, los receptores interesados de la propaganda, los que desean conocer la política del partido y los posibles candidatos a militante $o$ afiliados más o menos activos y los llamados «compañeros de viaje». Entre ellos se contaba con Blas de Otero en Bilbao, con Ribes en Valencia, con Jorge Renales y Ángela Figuera en Madrid y con Luis Landínez en Barcelona.

Todos estos datos confirman al PCE en sus expectativas optimistas para el trabajo político en España, que son las que su nueva orientación viene buscando e impulsando con denuedo. Para avanzar con ese rumbo la dirección comunista de París procuraba poner a todo su equipo en la misma sintonía de trabajo. De ahí que decidiera intervenir y actuar en la todavía fuerte organización de los comunis-

8 Autobiografía de Federico Sánchez, (AFS), Barcelona, 1977, pp. 199-200. V. igualmente MORÁN, G., Miseria..., pp. 205 y 225. Algunos de los colaboradores de Carrillo para el trabajo en España citados por este autor son: Romero Marín, Julián Grimau, Félix Pérez, Del Campo, Arrieta...

9 AFS, p. 180. Sobre la actividad de Ortega, AHPCE, Sección Dirigentes, caja 32, carpeta 11, años 1953 y 1954. Contiene su Autobiografía, 17 f., noviembre de 1953 (París). 
tas en México, poner un poco de orden y disciplina en una sección que iba demasiado libre por sus propios derroteros, atajar diversos conflictos e irregularidades que se venían produciendo desde años atrás y, en fin, atraerlos disciplinadamente a la senda que estaba abriendo desde París el equipo que cada vez más firmemente llevaba la voz cantante. Desde esos momentos queda de manifiesto que la dirección política está en manos de los dirigentes residentes en París. El exilio americano parece declinar en importancia y subordinarse a la nueva política hacia el interior desde el punto de dirección más próximo. En los próximos años se verán los resultados.

\section{CONSOLIDACIÓN Y AMPLIACIÓN DE LA ORGANIZACIÓN COMUNISTA DE LOS INTELECTUALES, 1954}

El año amaneció con un motivo de protesta inesperado, regalo del régimen franquista. Surgió de un error de cálculo de los jefes falangistas. Querían hacerse ruidosamente presentes en el escenario público del que se veían expulsados progresivamente. Tomando a los estudiantes como rehenes, bajo la cobertura de una reivindicación nacional, nada menos que el Peñón de Gibraltar, organizaron una aparatosa protesta que pretendían llegara a las alturas, españolas e internacionales ${ }^{10}$. Pero los estudiantes no se dejaron manipular. Espontáneamente, pero con energía, rechazaron el engaño y transformaron la inducida protesta nacional en un clamor contra el régimen y por la libertad.

En efecto, la visita de la reina de Inglaterra a la colonia de Gibraltar, proyectada para el mes de mayo, según Mundo Obrero, dio la ocasión a un SEU en proceso de creciente descrédito de promover y dirigir una protesta nacional de los universitarios españoles contra la diplomacia británica, considerada provocadora. Conocido es sobradamente cómo la manifestación del día 25 de enero, después de recorrer el centro de Madrid, tomando impulso en el Palacio de Santa Cruz con un discurso del ministro de Asuntos Exteriores, llegó ante la embajada británica donde la patriotera algarabía de protesta, armada convenientemente de piedras, fue duramente reprimida por la policía que protegía la sede diplomática, para chasco e indignación de los estudiantes, sorprendidos en su buena fe. La festiva protesta legal se trocó bruscamente en enfrentamiento violento con la policía, dejó tras de sí un saldo de heridos y, para los estudiantes, junto al encono sin atenuantes contra el SEU, la evidencia de que el régimen sólo disponía del recurso de la represión para seguir manteniendo su política ${ }^{11}$.

10 Según J. TUSELL, fue la Secretaría General del Movimiento la organizadora de la protesta juvenil. Los ministros se enteraron de la convocatoria cuando estaban reunidos en Consejo, Franco y los católicos. La política interior española entre 1945 y 1957, Madrid, 1984, p. 372.

11 LIZCANO, P. La generación del 56. La universidad contra Franco, Barcelona, 1981, pp. 95-100; JÁUREGUI F. y VEGA, P., Crónica del antifranquismo. I, Barcelona, 1983, pp. 169-173 que citan a Pablo Castellano entre los estudiantes detenidos; RUIZ CARNICER, M. A.: El Sindicato Español Universitario (SEU), 1939-1965. La socialización política de la juventud universitaria en el franquismo, Madrid, 
En el PCE se percibió de inmediato la trascendencia de lo ocurrido. Después de estos graves sucesos, al decir de las crónicas del informador del PCE, Celso, los estudiantes, ya decididos a la protesta contra las autoridades, se manifiestan ante la Dirección General de Seguridad y, reunidos con el general Hierro, exigen, incluso con modales violentos, el castigo de los policías que dispararon contra los manifestantes. El grueso de las protestas en días sucesivos se ha trasladado a la facultad de Derecho de la calle San Bernardo donde la represión policial arrecia y, por contra, el SEU ha desaparecido, del mismo modo justamente que la reclamación de Gibraltar, origen de los conflictos (o la de Tánger, que también en estos días era objeto de alguna reclamación propagandística por el régimen franquista en el contexto del enfrentamiento con Francia por la administración de Marruecos) ${ }^{12}$. El director de Mundo Obrero, Antonio Mije, lo expuso terminantemente en un escrito bajo el titular con que el órgano oficial abría la noticia, «Ayer en Barcelona, hoy en Madrid» ${ }^{13}$. Los españoles, los madrileños, que ven indignados los gibraltares concedidos por Franco a los americanos, se han manifestado contra el régimen y sus brutales métodos policiales, «con una gran sensibilidad política y demostrando una elevada conciencia, transformaron la manifestación en una acción política contra los verdaderos responsables de la venta de España...» y han acabado pidiendo la dimisión de Fernández Cuesta, Blas Pérez, Ruiz Jiménez, Arias Salgado y el general Hierro Martínez.

Las puertas abiertas por las «jornadas de Madrid», según los planteamientos de Mije, debieron de precipitar la vuelta de Jorge Semprún a Madrid. El día 3 de febrero se encuentra ya en su ciudad de nuevo. Rápidamente, como si fuera la vida en ello, está ante la máquina de escribir para trasmitir sus primeras impresiones sobre el terreno, en una curiosa correspondencia de circunstancias, próxima al reportaje periodístico. A su juicio, lo sucedido con los estudiantes es «más gordo de lo que se puede imaginar, entre otras cosas porque ha habido muertos... digo en plural porque hubo tres, casi seguramente ${ }^{14}$, y porque en la universidad han dimitido todos los delegados de curso del SEU ${ }^{15}$. El día 9 informa del deterioro político del SEU y de los jerarcas falangistas, incluido el ministro de Educación. También está afectado Laín, «muy maltrecho, abucheado e insultado públicamente por

\footnotetext{
1996, pp. 285-290; LAIN ENTRALGO, P.: Descargo de conciencia (1930-1960), Barcelona, 1976, pp. 170-178. Este autor, junto con Lizcano y Jáuregui-Vega, hablan del herido Muñoz Salvadores, estudiante de Derecho, de tendencia política monárquica. A propósito del carácter oficial de la convocatoria ante la embajada británica se refiere oficiosamente la petición del embajador inglés en conversación telefónica con el ministerio de Gobernación: «No me envíen más policías. Envíen menos estudiantes», apud Gabriel Elorriaga, intervención en los actos de conmemoración del 50 aniversario de los movimientos estudiantiles de febrero de 1956, celebrados en la Facultad de Ciencias Políticas y Sociología de la Universidad Complutense, 24 de febrero de 2006.

12 Informaciones sobre las manifestaciones estudiantiles, cartas de 28. 1. 1954 y de 29. 1. 1954, AHPCE, Fuerzas de la cultura, caja $123(2 / 2), 5 \mathrm{f}$.

${ }_{13}$ Mundo Obrero, 31 de enero de 1954. Se dice aquí, a diferencia de otros medios, que la protesta se organiza «ante la proyectada visita de la reina de Inglaterra en el mes de mayo a Gibraltar».

${ }_{14}$ Ninguna otra fuente o referencia historiográfica consultada confirma esta cifra.

15 Las Cartas de Jorge S. de este período llevan las fechas siguientes: 5. 2. 54; 9. 2. 54; 11. 2. 54; 16 2. 54 y 22. 2. 54, AHPCE, Fuerzas de la cultura, caja 123 (2), $6 \mathrm{f}$.
} 
los estudiantes, en una palabra desenmascarado. Ya no podrá especular fácilmente con su liberalismo».

Semprún transmite a la dirección parisina el clima que se ha encontrado en este segundo viaje ${ }^{16}$. El ambiente antifranquista parece predominar en las calles, en las conversaciones, en la conducta externa. Semprún dice percibir un sentimiento general antiyanki, o, en todo caso, una actitud de indiferente expectativa. Se permitió asistir al desfile de la victoria del 1 de abril. Allí no percibió interés alguno del público, que más bien aprovechaba la ocasión para darse un paseo en un día soleado. No había aplausos a las tropas ni saludos a la bandera. Hubo chanzas, por contra, cuando un camión se paraba en seco en medio del desfile, y sorpresa por la "chatarra bélica» americana que se exhibía por primera vez.

Encuentra Semprún que todo esto, trasladado a un nivel superior, expresa un reforzamiento de las posiciones democráticas, como si hubieran resurgido del pasado las viejas generaciones liberales, grupos de la intelectualidad burguesa, orteguistas o católicos, un fenómeno curioso que obliga a buscar el contacto con ellos, y con sectores, todavía imprecisamente definidos, como los que se desgajan de la Falange. «Pero, por encima de todo, (las posiciones democráticas) se refuerzan en las nuevas promociones, al calor y bajo la influencia, por indirecta que ésta sea, de nuestra ideología, de nuestra posición política, del enorme interés por la URSS».

En contraste con esto, al instructor del PCE le llama la atención el peso creciente de la iglesia en la sociedad y en la política, sobre todo a través de manifestaciones externas - año mariano, misiones...- omnipresentes, fruto de un concordato que «en los medios intelectuales ha causado escándalo». Percibe esta realidad, en lo que a su actividad cultural se refiere, en la ofensiva censoril eclesiástica sobre la cultura, con pastorales contra Baroja o Azorín, hasta el punto de que las protestas católicas han logrado impedir la difusión de un número de homenaje a Pío Baroja de la revista Índice, autorizado previamente por la censura gubernamental. «Desde este punto de vista, concluye Semprún, la censura más tenaz es la eclesiástica-moral... La organización de la lucha contra la censura, utilizando para ella todas las plataformas legales que puedan existir, o crearse, forma sin duda parte de nuestras tareas más inmediatas e importantes».

En la universidad cree Semprún que el partido comunista está en condiciones favorables para aumentar su presencia e influencia. La inquietud que se vive desde enero traduce una alta politización que Semprún, manos a la obra, ha empezado a orientar y encauzar pacientemente. Su apoyo fundamental ha sido Enrique Múgica, ya instalado en Madrid, matriculado de $4 .^{\circ}$ de Derecho en este curso. Venía de su ciudad natal, San Sebastián, donde hasta entonces estudiaba como alumno libre, adscrito a la Universidad de Valladolid. A través de Muñoz Suay y de

16 Sobre diversos aspectos del trabajo del Partido entre los intelectuales, s.a. (Joge emprúm), s.l., abril de 1954, AHPCE, Fuerzas de la Cultura caja 126. De este informe proceden las informaciones recogidas en el texto a continuación. 
Eduardo Ducay, Semprún se ha encontrado con Múgica, el cual, transcribe en el informe, «me ha reconocido» ${ }^{16 a}$.

Semprún se dedica a formar e informar a Múgica, a razón de dos reuniones por semana. El joven estudiante, culto, apasionado y con interés por la acción política, carece aún de experiencia, especialmente porque subestima las posibilidades reales existentes y porque no da importancia suficiente a la organización. Semprún corrige, matiza, responde a sus interrogantes y le orienta hacia la acción en la facultad de Derecho, sobre todo para ampliar el número de los colaboradores. Semprún desaconseja la creación de organismos ilegales como la FUE. Le invita, por el contrario, a luchar desde dentro del SEU: «matar al diablo con su propia espada», dice Semprún. Poco después lo aprobará por escrito la dirección del PCE desde París ${ }^{17}$. Semprún insiste en los objetivos de la lucha de los comunistas en ese momento: la consecución de las libertades, la independencia nacional y la crítica al pacto con los EE.UU. Cree que Múgica no acaba de verlos con claridad suficiente por ahora. Pero Semprún está convencido de que el sector estudiantil es uno de los más activos. Por eso, si otros le acompañan, su papel será decisivo: «El frente estudiantil, por sus peculiares características, puede ser uno de los sectores en que más fácilmente puede romperse la opresión franquista»18.

A lo largo de dos meses, Múgica ha puesto a Semprún en contacto con otros estudiantes con similares inquietudes culturales y políticas, algunos de los cuales acabarán siendo miembros incondicionales del grupo universitario comunista: Julián Marcos, estudiante de Filosofía y Letras y Derecho, con aficiones literarias que pone en práctica colaborando en alguna revista de poesía, y Jesús López Pacheco, estudiante de la misma facultad de Letras, poeta galardonado con un accésit al premio Adonais y novelista en ciernes ${ }^{19}$. Después de la reunión con Semprún, los tres aceptaron ser considerados «organizadores comunistas en la Universidad de Madrid. El 1 de abril celebramos, pues, en la Ciudad Universitaria, y bajo la protección eficaz de los jinetes de la Policía Armada que patrullaban todo aquel sector, dada la fecha, una reunión final con Pacheco y Múgica». La reconstrucción que el escritor Semprún hace, tiempo después, en la Autobiografía..., está ligeramente de-

16a Se conocieron en San Sebastián, en casa de Gabriel Celaya, durante el primer viaje de Semprún.

17 Carta dirigida a «Querido Federico», firmada por Víctor (Velasco, presumiblemente), 17 de marzo de 1954, AHPCE, Intelectuales y Movimiento Estudiantil, Jacq. 95.

18 Desde este «descubrimiento» de la capacidad movilizadora de los universitarios, el PCE insistirá en la importancia de su contribución a la lucha antifranquista. Se verá confirmada esta impresión con las noticias de las protestas estudiantiles de Sevilla de esos días: «Las manifestaciones estudiantiles de Sevilla contra el franquismo», que comenzaron en rechazo del aumento de tarifas en tranvías, Mundo Obrero, n. ${ }^{\circ}$, 31 de marzo de 1954.

19 El libro premiado, que Múgica cita en su Itinerario..., p. 36, lleva por título Dejad crecer este silencio, colección Adonais, Madrid, 1953. En la, llamémosle, «galería de retratos» de los militantes que proporciona Semprún al final de su informe, p. 41 traza uno muy positivo de este joven estudiante de 24 años, a punto de finalizar sus estudios de licenciatura. «Ha llegado al comunismo, escribe, por el camino de la atracción ideológica y también por su contacto con la clase obrera, cuando estuvo en el campo del Servicio Universitario de Trabajo, S.U.T., en Cudillero (Asturias). Aquí, los pescadores con los cuales consiguió adquirir confianza, se declararon ante él comunistas y le explicaron todas las razones de su miseria actual, los robos de la patronal y de los sindicatos de pesca», etc. 
sorientada en el tiempo — «aquel 1 de abril de 1955 cuando quedó constituido en un descampado de la Ciudad Universitaria el primer núcleo de estudiantes comunistas: con Jesús... con Julián y con Enrique... Julio Diamante... ${ }^{20} \mathrm{Ha}$ incluido a este último que, en realidad, en 1954, según los mismos informes semprunianos, no era sino una referencia interesante, - -el nombre de un estudiante de medicina y alumno del Instituto de Investigaciones y Experiencias Cinematográficas, IIEC. Entrarían en contacto pocos meses después.

En esa fecha simbólica, al término de la reunión referida, la organización comunista ha decidido llevar a cabo un trabajo legal amplio. Consistía en impulsar el Aula de Literatura en Derecho y dinamizar la de Filosofía y Letras por medio de López Pacheco. Se proponen también realizar un Congreso de escritores universitarios bajo la cobertura legal del SEU, invitando a escritores no universitarios, considerados de prestigio, como «Baroja, Cela, Ángela Figuera, Angel Crespo, Antonio [por Alfonso] Sastre, Aleixandre...» ${ }^{21}$ Los activistas comunistas habían de tratar de

20 AFS, p. 36.

${ }^{21}$ La idea de la celebración de un congreso de escritores jóvenes, de tanta repercusión para el movimiento antifranquista, ha tenido a posteriori muchas paternidades pretendidas. Por ejemplo TUSELL, X.: La oposición democrática al franquismo. 1939-1962, Barcelona, 1977, pp. 287, atribuye la propuesta a Dionisio Ridruejo. Jorge Semprún declaró rotundamente que Múgica inventó los Encuentros de Poesía, el Congreso..., en su conferencia pronunciada en los actos de conmemoración del 50 aniversario de los movimientos estudiantiles de febrero de 1956, celebrados en la Facultad de Ciencias Políticas y Sociología de la Universidad Complutense, 22 de febrero de 2006. LIZCANO, P., La generación...., p. 115 opina que «la idea de organizar un Congreso de Escritores Jóvenes pudo surgir de Julián Marcos y de Jesús López Pacheco... pero fue Múgica quien en definitiva la hizo suya e inició todos los contactos para su montaje», información que corrobora el mismo Múgica, Itinerario..., p. 36. También los dirigentes del partido en París se consideraban los verdaderos estrategas de cuanto el partido realizaba en España: «la misma idea del congreso de escritores jóvenes, eso se examinó aquí con Múgica», resume Santiago Carrillo, Entrevista a Santiago Carrillo, Madrid, 28 de enero de 1999. Aunque no se concreta, es probable que estas visitas de Múgica a la dirección del partido se produjeran en el verano de 1955. Completando la información reseñada de Semprún, es de interés lo que escribe un coetáneo de los hechos, Antonio FERRES. La idea del Congreso de Escritores Jóvenes, escribe, no es del año 1955, como sostiene la nota de la policía que se recoge en el libro Jaraneros y alborotadores editado por Roberto Mesa: «Jesús López Pacheco ya había hablado conmigo el año 54, y aun antes, de la organización del Congreso. Era una esperanza de libertad. Yo mismo envié un brevísimo artículo que publicó con mi firma el diario $A B C$ Nunca la policía me interrogó sobre esta publicación», en Memorias de un hombre perdido, Madrid, 2002, pp. 93-94. Por su parte el director de actividades culturales del SEU, Jaime Ferrán, se atribuye un alto papel en los preparativos del congreso al tiempo que silencia los nombres y las actividades de cualquier otro de los participantes: «Al salir de España era presidente de un congreso de escritores jóvenes... A él invité a todo el mundo, tuviera la ideología que tuviera. Pero al regresar me di cuenta de que todos los que habían estado conmigo en el Congreso estaban en la cárcel». Ferrán viajó por Estados Unidos y Europa de junio a diciembre de 1955, MARSAL, J. F., Pensar..., pp. 116 y 121. Ya decía el informe de Carlos Semprún en su Informe que Ferrán iba diciendo que «la idea del congreso era suya».

Ángel Crespo, uno de los poetas participantes propuestos, fue el fundador, con Gabino Alejandro Carriedo y Federico Muelas, de la revista El pájaro de paja. Salieron diez números entre 1950 y 1954. Colaboró asimismo en la revista Trilce, editada en Guadalajara entre 1952-1953 por el también citado en los Informes de Semprún Antonio Leyva junto a Suárez Puga. V. Ángel Crespo, con el tiempo, contra el tiempo, catálogo de la exposición en el Círculo de Bellas Artes, abril-julio de 2005, donde se recoge un texto autobiográfico ya publicado en Anthropos, el n. ${ }^{\circ}$ 97, Barcelona, 1989. La primera de estas revistas publicaría además una colección de libritos de poesía, entre ellos Paz y Concierto de Gabriel Celaya que Semprún cita en su informe. V. RUBIO, F.: Las revistas poéticas españolas, 1939-1975, Alicante, 2003 , pp. 154-157 y 245-251. Crespo militó unos pocos años en el partido comunista, según Ángel González, Entrevista, Madrid, 19 de enero de 2005. 
detentar la secretaría del congreso. En tercer lugar, acordaron impulsar la experiencia del SUT, tomando por la mano la circunstancia de que López Pacheco, colaborador con funciones directivas, ha recibido la oferta de dirigir algún centro el próximo verano, lo que podría beneficiar al partido como cantera de militantes futuros. Por último, acuerdan empezar a preparar el gran asalto al SEU mediante la participación en las elecciones a delegados de curso para el próximo año académico.

Junto a estos planes se concretó el trabajo «ilegal». Habría que ir atrayendo y aglutinando estudiantes, los simpatizantes actuales, que con el trabajo adecuado podrían integrarse en el partido en un futuro inmediato. Son más de treinta los nombres de estos estudiantes próximos, posibles candidatos a la militancia. Finalmente, se propone hacer "venir» a París a los ya militantes el próximo verano para completar su formación en la organización del partido ${ }^{22}$.

El cine es otro de los sectores a los que Semprún dedica muchas páginas en su correspondencia. Informa de los estrenos de películas españolas, cuenta algunas con detalle, resaltando las aportaciones políticas críticas. Destaca sobre todo las obras de Bardem-Berlanga, concretamente el estreno de Novio a la vista, con guión de ambos y dirección del segundo, que juzga muy positivamente. Cuenta que él mismo acaba de escribir una crítica que saldrá en el próximo número de $O b$ jetivo ${ }^{23}$. Semprún lamenta los descalabros que ha infligido la censura al film, para destacar después «la sorprendente calidad de la comicidad cinematográfica alcanzada por Berlanga y la maestría para manejar... los factores psicológico-sociales de la tipificación de los personajes y situaciones», por lo que es, a juicio del crítico, superior a Tati y sus «Vacaciones de Mr. Hulot».

En este sector, Semprún cuenta con la colaboración de «mi hermano Ricardo», en referencia Ricardo Muñoz Suay, junto a colaboradores imprescindibles del sector como Bardem, dotado de inteligencia y entrega a la causa, pero escasa formación política y Eduardo Ducay, un joven que, además de escribir en Índice e Ínsula, es alumno en el IIEC — ha sido ayudante de dirección de Berlanga- y trabaja en el tercer programa de Radio Nacional. Su trabajo en la distribución de propaganda ha sido muy valorado. Será la mano derecha de Muñoz Suay, sobre todo en Objetivo, la revista que, dice Semprún, "constituye en nuestras manos un arma importante... el Partido debe cuidar y prestarle toda la ayuda necesaria» ${ }^{24}$.

22 La reunión y los hipotéticos «cursos de verano» no tuvieron lugar. A París sólo acudieron Bardem y Muñoz Suay. Por razones diversas no lo hicieron Múgica, Nora, Celaya ni Ducay.

${ }_{23}$ «Novio a la vista. Rebelión de los adolescentes. 7», n. ${ }^{\circ} 3,(1954)$, pp. 32-34, firmada como Federico S. Artigas. El número 7 corresponde a la puntuación de calidad que la revista y el crítico atribuyen a la película.

${ }_{24}$ Objetivo, con su nombre de doble sentido, es la gran creación de los intelectuales comunistas en el sector cinematográfico. EI PCE siempre la consideró como una de sus criaturas. Apareció en 1953. Publicó nueve números en dos épocas, hasta 1955 en que cayó asfixiada por la censura y la administración franquista. Constituyó un intento de estudiar teóricamente el fenómeno cinematográfico, así como de ejercer una crítica intelectualmente fundada, más allá de las informaciones superficiales, habituales en el género. Bardem, Muñoz Suay y Ducay, los tres militantes comunistas, querían promover, teórica y profesionalmente, un nuevo cine español en el que la visión crítica de la realidad social española, lo que se denominaba muy genéricamente realismo, fuera una constante. El editor en su segunda época, a partir del quinto número, fue José Ángel Escurra. V. SALVADOR MARAÑÓN, A.: De ¡Bienvenido Mr. Marshall!..., pp. 106-112. 
En los medios literarios Semprún advierte una crisis de lo que llama «movimiento marginal de oposición intelectual», desorientados y faltos de medios y de posibilidades reales de incidencia ante los rápidos cambios que se están viviendo en la sociedad española en los últimos tiempos. Señala Semprún que el partido debe emplearse a fondo en ayuda de este sector intelectual «so pena de verse malograr una espléndida cosecha intelectual de contenido democrático». Semprún se informa de la situación del sector por medio de Múgica y de «el primo Eugenio» (de Nora), a quien no ve demasiado, aunque le ha convencido para que intervenga en el Aula de Literatura.

El caso más difícil ha resultado ser el de Gabriel Celaya. No se ha desplazado a Madrid ni acepta participar en el Aula de Literatura de Derecho, como le piden Múgica y Semprún. Cree éste, no obstante, que el partido debe seguir contando con él, entre otras cosas porque en este sector no son muchos los elementos fijos: Nora reside en Suiza y Blas de Otero parece sumido de nuevo en la crisis psicológica. De los contactos literarios de Múgica se destaca el grupo de Ángel Crespo y Antonio Leyva. «Previa discusión conmigo, Múgica lanzó aquí la idea de un Congreso de revistas y movimientos poéticos, idea que provocó gran interés».

Si se mira hacia los diferentes sectores profesionales también se encuentran dificultades para poner en marcha la actividad política en ellos. El partido cuenta con la incondicional colaboración de Hernández, si bien, como a tantos sucede, las obligaciones de subsistencia dejan poco tiempo libre. Semprún explica cómo se impone el esfuerzo de este ginecólogo para difundir la técnica soviética del parto sin dolor aprendida del Dr. Lamaze en París, en un país católico que recuerda a las mujeres el mandato bíblico «parirás con dolor», hasta el punto de que su tío, con mucho prestigio profesional pero renuente en principio al nuevo método, se está convirtiendo poco a poco en un defensor entusiasta a la vista de los primeros resultados obtenidos por su sobrino. Hernández ha inaugurado una nueva clínica en el barrio popular madrileño de Tetuán con un joven colaborador.

Un colaborador singular de Semprún, procedente de los medios intelectuales fue Eloy Terrón, en quien encontraría un apoyo sólido a lo largo de su trayectoria clandestina en Madrid. Terrón es licenciado en Filosofía y Letras, en la especialidad de filosofía, da clases en una academia privada y es ayudante en clases prácticas de Historia de la Filosofía Antigua en la cátedra de Montero Díaz. Semprún llegó a él por medio de una carta de «Vega, actualmente lector de español en Burdeos ${ }^{25}$. Semprún encuentra a Terrón muy encerrado en su mundo de libros; precisamente está enfrascado leyendo la Fenomenología del Espíritu de Hegel en alemán ${ }^{26}$. Tiene pocos contactos con la joven intelectualidad española por la que

25 José Vega Merino, leonés, hijo de un médico de la Armada y considerado «oveja negra» en su familia, formaba parte del grupo que se reunía en torno al sacerdote Antonio González de Lama en León. Entrevista a Eloy Terrón, Madrid, 2 de abril de 1998.

26 «Yo daba clase en la academia Colegio Arana, en la calle Claudio Coello. También en la universidad fui durante años ayudante de clases prácticas con Santiago Montero. (Emilio) Lledó y yo dimos cla- 
siente un cierto desprecio. ${ }^{27}$ Semprún le orienta hacia el trabajo universitario desde su puesto de profesor ayudante en la universidad. Del ilustre catedrático de Historia Antigua informa Semprún que está en posiciones antifranquistas, es adversario del pacto yanki-franquista y está muy interesado en la ciencia y en la cultura soviéticas. Terrón por su parte se compromete a colaborar en la revista Cuadernos de Cultura y a proporcionar información por escrito a la dirección del partido. Sin embargo Semprún lamenta la pérdida de la prevista colaboración de Luis Landínez a la vista de los imponderables surgidos.

A partir de toda esta información recopilada, Semprún formula en sus cartas e informes diversas propuestas que considera necesarias para atender las necesidades políticas que van surgiendo en los medios intelectuales. Constantemente viene insistiendo ante la dirección en la necesidad de incrementar los envíos de propaganda, siempre bien acogidos por sus receptores. En su segunda carta ya hacía notar, ante las perspectivas descubiertas, que lo «que vendría al pelo son aquellos artículos del primer tomo del filósofo Koba, jsi se pudieran dar a conocer! ${ }^{28}$ Pide que mejore la distribución. Informa de la buena aceptación de Lettres Françaises, recibida por Julián Marías, Paulino Garagorri (del consejo de redacción de Objetivo), Rafael Morales, José Luis Cano y Garciasol. Cree que sería interesante añadir otras como La Pensée, La Nouvelle Critique, Europe. Después de analizarlo detenidamente en varias reuniones con intelectuales, lectores y posibles colaboradores, propone que se mejore tanto la forma como el contenido de revistas como Cuadernos de Cultura, y que éste se relacione más directamente con España: «No hay que olvidar nunca que, cuando la revista llega a las manos de algún intelectual español, por confusas que aún sean sus ideas sobre el porvenir de España y sobre los problemas filosóficos o estéticos, será muy exigente para con nosotros, y eso porque en el fondo, e incluso sin darse cuenta, sólo de nosotros espera orientaciones y directivas» (subrayado en el original). En el supuesto de que

ses de Historia de la Filosofía Antigua (también Lledó dio clases en la misma academia Arana). Un día Semprún se me presentó en Ibiza 5, habitación que tenía alquilada desde noviembre de 1952... (diciendo) que venía de parte de unos amigos de París. Ni me llamó. Me causó una impresión tremenda, bien vestido, alto, pelo cortado a cepillo, las chicas se volvían locas (me lo han hablado a veces). Yo estaba traduciendo la Introducción a la Historia de la Filosofía de Hegel... Jorge a veces me ayudaba en la traducción. Una vez, en la pensión, llamaron por teléfono, la patrona dijo que llamaban al señor, por Semprún, y estuvo hablando en alemán, y me dice la dueña, qué bien habla el alemán, debe ser de la zona de Berlín, y yo le dije no es alemán, pues habla muy bien, dijo ella, que sabía alemán, era hija de un capitán de barco alemán y una española... ella me ayudaba también en las traducciones...» Entrevista a Eloy Terrón, loc. cit.

${ }_{27}$ Esto cambiará poco después cuando comience su tesis doctoral, dedicada precisamente al pensamiento español, por indicación de Montero Díaz. Terrón se mostró pronto muy agradecido por ese consejo que supuso un cambio radical en su vida. Significó de hecho «el descubrimiento de España, el descubrimiento de que nosotros también tenemos una historia no menos viva y vigorosa que la de cualquier otro país», en JEREZ MIR, R.: «Eloy Terrón Abad (1919-2002): el hombre y el marxista. Una aproximación bio-bibliográfica», Papeles de la FIM, n. 21 (2003), 2. ${ }^{\circ}$ semestre, pp. 145-146. Proceden estas páginas del «Epílogo a la tesis 'La Filosofía krausista española'», 11 pp., fechado en Madrid, 27-29 de diciembre de 1959, en AHPCE, Fuerzas de la Cultura, caja 126.

${ }_{28}$ El filósofo de tal nombre no era otro que Stalin que había usado este sobrenombre desde la juventud. 
se cumplieran las mejoras propuestas, piensa Semprún, podría llegar un día no lejano en que Cuadernos... se editara en España. O, mejor todavía, lograr la creación de una revista legal del partido.

\section{CONCLUSIONES: PERSPECTIVAS Y PROYECTOS}

Las conclusiones que presenta Semprún después de sus dos meses de estancia en España en este segundo viaje del año 1954, se centran en cómo organizar y encauzar el caudal de posibilidades de trabajo entre los intelectuales en un momento de cierta agitación, con la lucha por las libertades que preocupan a los intelectuales como objetivo central, y coincidiendo todo ello con lo que considera un momento de avanzada descomposición del régimen. A tal punto ha llegado la situación a su juicio, que son muchos los que toman posiciones para situarse de cara al futuro. Los católicos, ocupando el lugar que deja una Falange moribunda, pretenderán limitar al mínimo los cambios. Por eso advierte de que «en el terreno intelectual, concretamente, la Iglesia constituye hoy, desde el punto de vista ideológico y de organización, nuestro más serio adversario».

De la misma Falange se desgajan algunas figuras representativas. Dionisio Ridruejo es el más importante. Según le cuentan, y Semprún transmite en su informe, «está desenfrenado». El sector que encabeza, «ala «liberal» o «republicana» o «integradora» que hemos venido llamando «ridruejista» por la comodidad de la formulación", es el más temido por los católicos que lo ven como peligroso competidor. Informa Semprún de que está multiplicando los contactos, contando con Laín, Figueroa, hasta el mismo Serrano Súñer y con algún representante socialista, para crear una plataforma que, sin violencia, constitucionalizara un régimen nuevo, sin partido único, permitiendo varios, «no el nuestro», y él mismo constituiría una nueva formación, frente a las tradicionales reaccionarias, de carácter obrero, modernizada, en la que gentes como Prieto podrían tener cabida. Su objetivo más preciso es «neutralizar a los comunistas» y a la política revolucionaria que representan, por un serio peligro de competencia, más insuperable en una situación como la española que en un régimen como el francés. Para su agrupación de fuerzas parece que quiere contar con figuras de antiguo renombre liberal como Ortega, Baroja y Menéndez Pidal. Así se entiende por qué Índice dedicó un número extra al novelista vasco y por qué fue atacado con saña por la iglesia católica hasta impedir su difusión en España.

Semprún propone a su partido intensificar su trabajo, volcarse con los intelectuales, formarles en los principios correspondientes a un partido de la clase obrera y organizarles en los sectores indicados: «Más valen unas cuantas organizaciones sólidas que una infinidad de contactos más o menos inconexos y amorfos". De seguir estas pautas se llegará a sentar las bases para la constitución del Frente Nacional Antifranquista, objetivo máximo de la organización comunista en esos momentos. 
Si se atiende a la formación y al estudio de los principios del marxismo-leninismo y se logra consolidar los órganos de propaganda de forma regular, será posible extender y estabilizar una organización comunista de los intelectuales. En el horizonte de la lucha por la independencia nacional y por un gobierno democrático provisional se establecerá una plataforma con otras fuerzas burguesas antiyankis para dar forma al Frente Nacional: «A este respecto», concluye el informe, «y asegurando en cada caso la protección de nuestra organización clandestina, me parece que es posible actuar con audacia y decisión, abordando directamente a toda una serie de personas o grupos, en nombre del Partido y con miras a la lucha por la independencia nacional».

En el balance de la información transmitida por Semprún es de destacar ante todo que ésta constituye el apoyo más sólido para la política cultural del partido en los próximos años. Una política planteada con el optimismo de las expectativas favorables y avalada por el descubrimiento indiscutible de un campo fértil, abierto al porvenir, representado por la nueva generación, que se siente más libre de compromisos con el pasado y más dispuesta a conquistar un futuro diferente del presente opresivo.

El optimismo que transmiten las informaciones de Semprún se basa en los progresos realizados en tan poco tiempo. No dejaba de alimentarse también de los ingredientes a priori repetidos en los documentos comunistas. El convencimiento de la debilidad del franquismo es uno de ellos. Quienes como Muñoz Suay, que «todavía ve franquismo durante años y años" y, en consecuencia, carecen de confianza en la victoria, son objeto de crítica. Lo mismo se diga de las afirmaciones de apoyo y simpatía a la política de la URSS o de su anverso, el rechazo a todo lo yanki. También es de notar el valor que todavía concede Semprún y el partido al valor formativo de los textos de Stalin, muerto en marzo del año anterior. El descubrimiento de España queda enmarcado en la visión política dimanada de la ideología comunista. Las distorsiones entre ambos planos que de ahí nazcan obligarán a rectificaciones y ajustes, muchas veces suficientes, otras no bien comprendidos y aceptados por todos.

En el escaso tiempo de que ha dispuesto Semprún ha tomado o ha propuesto tomar decisiones trascendentales para la lucha antifranquista del PCE. Semprún ha hecho que intervenga Eugenio de Nora en el Aula de Poesía y que esa actividad cobre impulso en el conjunto de la actividad política de los comunistas. Con Múgica y López Pacheco, de común acuerdo, ha decidido celebrar el Congreso de Escritores Universitarios (pronto llamado de Escritores Jóvenes) para el ya inminente mes de mayo. Y, apoyado en la propuesta de Múgica, ha sugerido la celebración de un Congreso de Revistas Literarias, otra idea interesante que tampoco lograría llevarse a término completo, pero era un síntoma de vitalidad creativa y se convirtió en fuerza de la lucha estudiantil a partir de ese momento. Por último, consta por primera vez apuntado el deseo de sectores cualificados de la población española de dejar de lado cualquier propuesta basada en el ejemplo de la Guerra Civil. 
Toda la información que transmite Semprún configura una visión de España, a través de la actividad cultural y sus gentes, viva, dinámica, fértil, con deseos de cambio, una sociedad que, para sorpresa de los comunistas y otros viajeros, no yace aplastada por la dictadura que la gobierna. Leída hoy, la propuesta sempruniana evidencia la voluntad magnificadora del papel y la capacidad del PCE como la fuerza llamada a dirigir toda la lucha de los intelectuales españoles. Pero el descubrimiento de las capacidades de la sociedad española en la lucha por su liberación de la tiranía, presentes en embrión en la nueva generación, dispuesta a afrontar riesgos ya no tan peligrosos como los afrontados en la década precedente, constituye un gran paso para la extensión de la influencia comunista entre las gentes de la cultura española de los próximos años y para el desarrollo general de la lucha antifranquista.

Efectos políticos de todos estos planteamientos serán los incidentes universitarios con sus graves repercusiones políticas que tendrán lugar a lo largo del curso $1955-1956$. 